only, nor, in the long run, necessarily the best method, since the organic matter is rapidly oxidized and the conditions under which it accumulates are destroyed. Wet cultivation of suitable crops (for example, rice) or use of the nutrients for fish culture are possible alternatives. But too little is known about the chemistry and biology of swamps and of the changes which occur on drying. It is the purpose of this scheme to provide information which may assist in framing a long-term policy. The main chemical and microbiological transformations in the water-logged material, the ecology of the swamp vegetation, the biology of the oligochrte worms and other invertebrates and their part in the processes of decomposition, the adaptation of fish to swamp conditions, and the scarcity in untouched swamps of the principal malarial mosquito, Anopheles gambiae, are some problems which require investigation. All of them are of practical importance; but there are some aspects which are of fundamental interestfor example, the adaptations to a predominantly anaerobic environment. Work has already been started by Prof. L. C. Beadle in the zoological field and in the botanical field by Dr. Edna M. Lind, reader in biology at Makerere College, and the East Africa Malaria Research Institute has been collaborating. With the new Nuffield grant it is now possible to employ a chemical microbiologist and a zoologist from Europe, and two graduates from Makerere College.

\section{West African Tsetse Flies}

The taxonomy and systematics of tsetse flies from the Congo region belonging to the Glossina palpalis group-that is, to the sub-genus Nemorkina-which are of considerable importance from the medical point of view, since they carry human trypanosomiasis, have been the subject of an intensive study by A. de Barros Machado in a work entitled "Révision systématique des Glossines du groupe palpalis (Diptera)" (Pub. Cult. No, 22, Museu do Dundo; pp. $189+107$ figs. +8 tables; Lisboa: Companhia de Diamantes de Angola, 1954). Intensive collecting was carried out by the author over Angola and the Belgian Congo. Much of the investigation was carried out in the Museum of Dundo; but this was supplemented by work in the British Museum, the London School of Hygiene and Tropical Medicine, the Museum of the Belgian Congo and the University of Porto. Thus practically the whole of the relevant material, including type material, was critically examined and compared. The specimens are carefully described morphologically, particular attention being paid to the copulatory organs and the range of each species and sub-species considered and illustrated. There are no plates; but the excellence of the paper and reproduction of the many photomicrographs renders them unnecessary. The geographical distribution of each form is carefully determined. The one distribution that appears remarkable is that of Glossina tachinoides, which has its main centre between long. $10^{\circ} \mathrm{W}$. and $20^{\circ} \mathrm{E}$. (thero is a slip in the text on p. 151 which on line 7 gives longitude $10^{\circ} \mathrm{E}$. instead of $10^{\circ} \mathrm{W}$.) and a small subsidiary centre in the Sudan near longitude $34^{\circ} \mathrm{E}$. As the author points out, another record of this species from the south-west of Arabia cannot be regarded as satisfactorily established. In passing, it is interesting to note that the form along the border of Tanganyika is Glossina fuscipes martinii, while that along the Uganda border is G. fitscipes fuscipes. The author recognizes and treats fully Glossina fuscipes, $G$. palpalis and $G$. pallicera, all of which are polytypic, and G. tachinoides. What is known of the ecology and inter-subspecific fertility of the various forms is adequately set forth and discussed. The paper is extremely well printed and will undoubtedly form a classical work of reference for future work.

\section{Coconut Milk Growth Factors and Tumorous Growth}

IN further investigations of the growth and metabolism of plant cells, F. C. Steward, S. M. Caplin and E. M. Shantz (Ann. Bot., N.S., 19, 29; 1955) have considered the phenomenon of tumorous growth in its relation to growth factors of the kind found in coconut milk, that is, the liquid endosperm of Cocos nucifera. This new investigation stems from the observation that coconut milk can induce rapid proliferation in cultures of certain mature tissues (carrot root explants consisting of secondary phloem), that is, in cells which would not normally have undergone further division-a result, in short, reminiscent of the growth of plant tumours. These investigators have now shown that aqueous extracts of plant tumours, induced by Agrobacterium tumefaciens on Bryophyllum and Kalanchöe, can be used as a substitute for coconut milk in the tissue-culture procedures used in their laboratory. On the basis of extensive experiments they have shown that tumours of this kind yield extracts possessing a growthpromoting effect similar to that of coconut milk. This effect may be enhanced by, though it is distinguishable from the effect of, added casein hydrolysate in the basic medium. T'umour extracts were consistently more active than extracts of stems and leaves of the same plants, and of normal, nontumorous plants. The effect of coconut milk, which is replaceable wholly or in part by tumour extracts, is primarily an effect on cell division in the carrot tissue.

\section{Zygotropism in Mucor}

IN further physiological studies of the Mucorales, G. H. Banbury has investigated the zygotropism of the zygophores of Mucor mucedo (J. Exp. Bot., 6, 17, $235 ; 1955)$. In addition to positive zygotropism between $(+)$ and $(-)$ zygophores, there is claimed to be a corresponding 'repulsion' between zygophores of the same mating type, $(+)$ from $(+)$ and $(-)$ from (-). The stimulus appears to be transmitted by the diffusion of a volatile substance from one zygophore to another. A tentative explanation of the phenomena described is advanced, based on two postulated volatile hormones, each evolved by zygophores of one mating type only, stimulating growth in zygophores of its own mating type and retarding it in those of the opposite type. The results of these new investigations appear to dispose of the 'mitogenic ray' and 'accidental contact' theories of earlier workers.

\section{Visual Education}

IN co-operation with Unesco, the Central Council for Health Education has produced the latest issue of its Health Education Journal as a symposium on visual education (13, No. 1). The contributors are drawn from many parts of the world and, besides members of the Council's own staff, include such distinguished people as "Fougasse" on propaganda posters and Walt Disney on the development of animated cartoons. The use of moving films in combating human and animal disease in Tanganyika 